\title{
Produção de cultivares de tomateiro em hidroponia e fertirrigação sob razões de nitrogênio e potássio
}

\author{
Gláucio C Genuncio; Renata AC Silva; Núbia M Sá; Everaldo Zonta; Adelson P Araújo \\ UFRRJ-Dep ${ }^{\text {to }}$ Solos, BR 465 km 7, 23890-000 Seropédica-RJ; glaucio@ufrrj.br; ezonta@ufrrj.br; aparaujo@ufrrj.br
}

\begin{abstract}
RESUMO
Os cultivos protegidos de tomate apresentam elevada demanda por potássio para altas produções e qualidade de frutos, não tendo sido estudada suficientemente a relação de aplicação entre nitrogênio e potássio que proporcione tais resultados. Avaliou-se a produção e qualidade de frutos de quatro cultivares de tomateiro em sistemas de cultivo hidropônico e fertirrigado sob duas razões entre $\mathrm{N}$ e $\mathrm{K}$ fornecidas às plantas. Dois experimentos foram conduzidos simultaneamente em casa de vegetação, em esquema fatorial $4 \times 2$ com quatro repetições, combinando quatro genótipos (cvs. Cereja 261, San Marzano, Santa Clara e o híbrido Cereja Chipano) com duas razões N:K (1:1,5 e 1:2 no hidropônico, e 1:2 e 1:3 no fertirrigado). A produção média de frutos comerciais foi de 2,5 e 1,8 kg/planta no sistema hidropônico e fertirrigado, respectivamente, atingindo $3,3 \mathrm{~kg} /$ planta na cv. Santa Clara em hidroponia. Em hidroponia, as razões $\mathrm{N}: \mathrm{K}$ não afetaram a produção de frutos comerciais e o teor de sólidos solúveis, apesar de um aumento de $6,5 \%$ na produção na razão $\mathrm{N}: \mathrm{K} 1: 2$. A razão $\mathrm{N}: \mathrm{K}$ 1:2 em hidroponia aumentou a massa e o diâmetro médio dos frutos comerciais, reduzindo a concentração de $\mathrm{K}$ nos frutos. No sistema fertirrigado, a razão $\mathrm{N}: \mathrm{K}$ 1:3 estimulou o crescimento vegetativo do tomateiro, mas não afetou a produção e a qualidade dos frutos. As cultivares San Marzano e Santa Clara tiveram maior produção de frutos nos dois sistemas. A produção de frutos e o teor de sólidos solúveis das cvs. San Marzano e Santa Clara foram maiores no sistema hidropônico em comparação ao fertirrigado. O sistema hidropônico propiciou maior produção de frutos que o sistema fertirrigado para as cultivares San Marzano e Santa Clara e, em hidroponia a razão $\mathrm{N}: \mathrm{K}$ 1:2 forneceu frutos de maior qualidade comercial.
\end{abstract}

Palavras-chave: Solanum lycopersicum, cultivo protegido, razão $\mathrm{N}: \mathrm{K}$.

\begin{abstract}
Production of tomato cultivars in hydroponics and fertigation with different ratios between nitrogen and potassium

Protected tomato cultivation presents a high potassium demand for obtaining high fruit yield and quality, but the ratio between nitrogen and potassium supplies which provides such results has not been sufficiently evaluated. The fruit yield and quality of four tomato cultivars were evaluated in hydroponics and fertigation systems at two ratios between $\mathrm{N}$ and $\mathrm{K}$ provided to the plants. Two experiments were carried out simultaneously in greenhouse, in $4 \times 2$ factorial design with four replicates, comprising four genotypes (cultivars Cereja 261, San Marzano, Santa Clara and the hybrid Cereja Chipano) and two N:K ratios (1:1.5 and 1:2 in hydroponics, and $1: 2$ and $1: 3$ in fertigation). Average yield of marketable fruits was 2.5 and $1.8 \mathrm{~kg} /$ plant in the hydroponics and fertigation system, respectively, reaching $3.3 \mathrm{~kg} /$ plant for cv. Santa Clara in hydroponics. In hydroponics, the $\mathrm{N}: \mathrm{K}$ ratios nor did affect fruit production nor the soluble solids concentration, but the marketable fruit yield increased $6.5 \%$ at the $\mathrm{N}: \mathrm{K}$ ratio $1: 2$. The $\mathrm{N}: \mathrm{K}$ ratio $1: 2$ in hydroponics increased the average mass and diameter of marketable fruits, reducing $\mathrm{K}$ concentration in fruits. In the fertigation system, the $\mathrm{N}: \mathrm{K}$ ratio $1: 3$ stimulated the vegetative growth of tomato plants but did not affect the fruit quality and yield. The cultivars San Marzano and Santa Clara presented higher fruit yield in both experiments. Fruit yield and total soluble solids of San Marzano and Santa Clara were higher in the hydroponics system when compared to fertigation. The hydroponics system provided higher fruit yield than the fertigation system for San Marzano and Santa Clara and, in hydroponics, the N:K ratio 1:2 improved fruits with higher marketable quality.
\end{abstract}

Keywords: Solanum lycopersicum, protected cultivation, N:K ratio.

\section{(Recebido para publicação em 11 de dezembro de 2009; aceito em 1 de outubro de 2010) (Received on December 11, 2009; accepted on October 1, 2010)}

\begin{abstract}
A s técnicas de cultivo protegido do tomateiro buscam minimizar as perdas causadas pelas adversidades climáticas e ambientais, além de otimizar o uso de insumos. O cultivo do tomateiro em ambiente protegido no período de entressafra pode propiciar produtividades superiores a $100 \mathrm{t} \mathrm{ha}^{-1}$ em ciclos de 150 dias (Andriolo et al., 1997). Dentre os sistemas de cultivo protegido destacam-se a hidroponia, definida como um cultivo sem solo onde as raízes recebem uma solução nutritiva balanceada, e a fertirrigação,
\end{abstract}

onde os fertilizantes são aplicados em conjunto com a irrigação, propiciando menores perdas de nutrientes (Moraes, 1997; Hebbar et al., 2004). Informações mais detalhadas sobre a nutrição mineral do tomateiro em cultivo protegido são essenciais para a definição de dosagens adequadas de fertilizantes, objetivando o máximo rendimento e elevado padrão de qualidade dos frutos.

O tomateiro destaca-se entre as hortaliças cultivadas por ser extremamente exigente em nutrientes, apresentando demandas diferenciadas de acordo com os estágios de desenvolvimento, com a duração do ciclo de cultivo, com o genótipo e com a época do ano (Moraes, 1997). O K é o nutriente absorvido em maiores quantidades pelo tomateiro, tanto em condições de campo quanto em cultivos protegidos (Gargantini \& Blanco, 1963; Fayad et al., 2002), e são elevadas as demandas por $\mathrm{K}$ em cultivos protegidos para o crescimento vegetativo, produção de frutos e qualidade dos frutos (Kanai et al., 2007). O fornecimento insuficiente de $\mathrm{K}$ tem sido inclusive constatado em cultivos co- 
merciais de tomate (Chen \& Gabelman, 2000). A manutenção de uma razão de fornecimento de $\mathrm{N}$ e $\mathrm{K}$ em torno de 1:2 e 1:3 na fase de enchimento de frutos, associada a um controle eficiente da irrigação, aumenta a qualidade de frutos (Prados, 2001).

$\mathrm{O} \mathrm{K}$ atua na regulação da abertura estomática, a qual se relaciona diretamente com a fotossíntese e em conseqüência com a síntese de fotoassimilados, além de atuar como ativador enzimático (Taiz \& Zeiger, 2004). A deficiência de $\mathrm{K}$ limita a fotossíntese nas folhas e o transporte de fotoassimilados para os frutos de tomate, causando redução no número e tamanho de frutos através de uma limitação na atividade do dreno (Kanai et al., 2007). Doses adequadas de $\mathrm{K}$ podem aumentar a produção e a qualidade comercial de frutos de tomate (Fontes et al., 2000).

Em trabalhos avaliando a adaptação de cultivares e/ou híbridos para o cultivo protegido do tomate foram verificadas variações nas produtividades, em razão de interações entre genótipos e ambientes e práticas culturais adotadas nos diferentes ensaios (Gualberto et al., 2002; Caliman et al., 2005). Quando se associam genótipos com alto potencial produtivo e manejo de condições ambientais favoráveis, obtem-se elevada produtividade, proporcionando aumentos de produção de 25 a $40 \%$ devido à maturação precoce, melhor uniformidade, maior vigor inicial e desenvolvimento, melhor qualidade de frutos e resistência a doenças (Melo et al., 1988).

Foram conduzidos dois experimentos simultâneos em ambiente protegido, com o objetivo de avaliar a produção e a qualidade de frutos de quatro cultivares de tomateiro em sistemas de cultivo hidropônico e fertirrigado, sob duas razões $\mathrm{N}: \mathrm{K}$ fornecidas às plantas.

\section{MATERIAL E MÉTODOS}

Foram conduzidos dois experimentos simultâneos de junho a novembro de 2007, sendo um em cultivo hidropônico e outro em cultivo fertirrigado, em casa de vegetação da UFRRJ, em Seropédica-RJ. Cada experimento teve delineamento em blocos ao acaso em arranjo fatorial $4 \times 2$ com quatro repetições, combinando três cultivares (Cereja 261, San Marzano e Santa Clara) e um híbrido comercial (Cereja Chipano) de tomateiro (Solanum lycopersicum), com duas diferentes razões de fornecimento de $\mathrm{N}$ e $\mathrm{K}$ (razões $\mathrm{N}: \mathrm{K} 1: 1,5$ e 1:2 no hidropônico, e 1:2 e 1:3 no fertirrigado). A cultivar Cereja 261 e o híbrido Cereja Chipano apresentam ciclo de 90 dias, crescimento indeterminado, diâmetro médio de frutos de 3 a $4 \mathrm{~cm}$ e massa de frutos entre 18 e 23 g (Isla, 2009). A cultivar San Marzano (tipo italiano) tem ciclo de 110 dias, crescimento indeterminado, diâmetro médio de frutos de $4 \mathrm{~cm}$ e massa de frutos entre 60 e 70 g (Isla, 2009). A cultivar Santa Clara (tipo salada) tem ciclo de 110 dias, crescimento indeterminado, diâmetro médio de frutos de $9 \mathrm{~cm}$ e massa de frutos de $180 \mathrm{~g}$ (Isla, 2009).

A semeadura foi realizada em junho de 2007, em substrato de fibra de coco em bandejas de poliestireno. Aos 15 dias após a semeadura, as plântulas receberam solução de Hoagland \& Arnon diluída a $1 / 4$, e 35 dias após a semeadura foram transplantadas para os locais definitivos.

O experimento hidropônico foi conduzido em sistema tipo NFT (fluxo laminar de nutrientes), que consiste em uma solução nutritiva fornecida de forma intermitente, de modo que ocorra plena disponibilidade de oxigênio às raízes. Foram utilizados 12 perfis de polipropileno com $10 \mathrm{~m}$ de comprimento, e espaçamento de $0,6 \mathrm{~m}$ entre fileiras duplas, $0,5 \mathrm{~m}$ entre plantas e 1,0 $\mathrm{m}$ nas ruas, com 16 plantas por linha. A unidade experimental útil consistiu de quatro plantas por parcela, descontandose as plantas de bordadura localizadas externamente aos tratamentos e entre as cultivares. As plantas foram tutoradas individualmente com fios de polietileno presos a fios de arame. Empregou-se solução de Hoagland \& Arnon com $50 \%$ da concentração iônica (descrita por Genuncio et al., 2006), sendo as quantidades de $\mathrm{Ca}\left(\mathrm{NO}_{3}\right)_{2}$ e $\mathrm{KNO}_{3}$ modificadas para atingir as duas razões $\mathrm{N}: \mathrm{K}$ estudadas; a razão $\mathrm{N}: \mathrm{K} 1: 1,5$ foi complementada com $\mathrm{CaCl}_{2}$. As soluções possuíam 103 e $153 \mathrm{mg} \mathrm{L}^{-1}$ de $\mathrm{N}$ e K, respectivamente, na razão 1:1,5, e 103 e $204 \mathrm{mg} \mathrm{L}^{-1}$ de $\mathrm{N}$ e K na razão 1:2. As soluções eram aplicadas a intervalos de 15 min intercalados entre irrigação e aeração, com uma vazão de $4 \mathrm{~L} \mathrm{~min}^{-1}$ para cada canal. As soluções eram monitoradas através da condutividade elétrica, sendo renovadas a cada 15 dias.

O sistema fertirrigado foi conduzido em substrato de fibra de coco, acondicionado em recipientes de polipropileno de $8 \mathrm{~L}$ e irrigação por gotejamento, sendo utilizadas as doses de $150 \mathrm{~kg} \mathrm{ha}^{-1}$ de $\mathrm{N}$ e $50 \mathrm{~kg} \mathrm{ha}^{-1}$ de $\mathrm{P}$, combinadas com as doses de 300 e $450 \mathrm{~kg} \mathrm{ha}^{-1}$ de $\mathrm{K}$, o que resultou nas razões $\mathrm{N}: \mathrm{K}$ de 1:2 e 1:3. As doses em $\mathrm{kg} \mathrm{ha}^{-1}$ foram convertidas por planta, considerando a densidade de 2,4 plantas por $\mathrm{m}^{2}$ dentro da casa de vegetação. O espaçamento adotado foi idêntico ao hidropônico, sendo a parcela útil constituída por quatro plantas. Os nutrientes foram distribuídos semanalmente através da água de irrigação e utilização de tensiômetros, seguindo-se a distribuição para cada fase do ciclo descrita por Alvarenga et al. (2004). Foram realizadas medições semanais da uniformidade da irrigação por vaso por amostragem em 20\% dos gotejadores.

A temperatura e a umidade relativa do ar foram registradas diariamente nos horários de 9 e $15 \mathrm{~h}$. Durante o período experimental, os valores médios foram de $65 \%$ de umidade relativa, e 28,3, 23,1 e $33,0^{\circ} \mathrm{C}$ de temperatura média, máxima e mínima, respectivamente.

Os frutos fisiologicamente maduros (coloração rósea) foram colhidos semanalmente em quatro plantas por parcela, entre os 128 e 153 dias após semeadura no sistema hidropônico e entre 115 e 148 dias no sistema fertirrigado. Em cada fruto colhido, foram determinados a massa fresca e o diâmetro transversal com o uso de paquímetro. $\mathrm{O}$ diâmetro dos frutos e a presença de lesões causadas por agentes bióticos (como requeima, rachaduras, broca pequena e broca grande) e abióticos (como podridão apical e lóculo aberto) foram utilizados para classificar os frutos como comerciais e não comerciais. Em uma amostra dos frutos de cada parcela, foram determinados os teores de sólidos solúveis totais ( $\left.{ }^{\circ} \mathrm{Brix}\right)$ através de refratômetro de campo, a acidez titu- 
lável através da titulação da polpa por solução de hidróxido de sódio $0,1 \mathrm{M}$, e o pH através de potenciômetro (Instituto Adolfo Lutz, 1985).

Ao final do ciclo as plantas foram colhidas, determinando-se a sua altura. Os caule, folhas e frutos foram secos em estufa a $70^{\circ} \mathrm{C}$ e pesados, obtendo-se sua massa seca. Após moagem, amostras dos frutos sofreram digestão sulfúrica, e no extrato foram determinadas as concentrações de $\mathrm{N}$ pelo método semi-micro Kjeldahl e de K através de fotômetro de chama (Tedesco et al., 1995).
Foi efetuada a análise de variância em um esquema fatorial, avaliando-se o efeito de cultivar, doses de K e suas interações, para cada experimento, sendo as médias comparadas pelo teste de Duncan a 5\%. Considerando que os experimentos em hidroponia e fertirrigação foram conduzidos simultaneamente e dispunham do mesmo delineamento experimental, foi também efetuada uma análise de variância conjunta dos dois experimentos, considerando um esquema fatorial triplo entre experimentos, cultivar e dose de $\mathrm{K}$, sendo as médias comparadas pelo teste de Duncan a $5 \%$.

\section{RESULTADOS E DISCUSSÃO}

No experimento realizado em hidroponia, as razões $\mathrm{N}: \mathrm{K}$ não modificaram a altura das plantas de tomateiro, a produção de frutos comerciais, o pH, o teor de sólidos solúveis, e a acidez titulável nos frutos, mas a razão N:K 1:2 aumentou a massa de folhas das cultivares Cereja 261 e San Marzano (Tabela 1). Cabe

Tabela 1. Características vegetativas, qualidade de frutos e teores de $\mathrm{N}$ e $\mathrm{K}$ na massa seca dos frutos de quatro cultivares de tomateiro em cultivo hidropônico sob duas razões N:K na solução nutritiva (vegetative characteristics, fruit quality and concentrations of $\mathrm{N}$ and $\mathrm{K}$ in fruits of four tomato cultivars grown in hydroponics with two N:K ratios in nutrient solution). Seropédica, UFRRJ, 2007.

\begin{tabular}{|c|c|c|c|c|c|c|c|c|c|}
\hline \multirow{2}{*}{ Cultivar } & $\begin{array}{c}\text { Razão } \\
1: 1,5\end{array}$ & $\begin{array}{c}\text { Razão } \\
1: 2\end{array}$ & Média & $\begin{array}{c}\text { Razão } \\
1: 1,5\end{array}$ & $\begin{array}{c}\text { Razão } \\
1: 2\end{array}$ & Média & $\begin{array}{c}\text { Razão } \\
1: 1,5\end{array}$ & $\begin{array}{l}\text { Razão } \\
1: 2\end{array}$ & Média \\
\hline & \multicolumn{3}{|c|}{$\begin{array}{c}\text { Altura da planta } \\
(\mathrm{cm})\end{array}$} & \multicolumn{3}{|c|}{$\begin{array}{c}\text { Massa seca de folhas } \\
\left(\mathrm{g} \mathrm{planta}^{-1}\right)\end{array}$} & \multicolumn{3}{|c|}{$\begin{array}{c}\text { Massa seca de caule } \\
\left(\mathrm{g} \text { planta }^{-1}\right)\end{array}$} \\
\hline Cereja 261 & 160 & 168 & $164 \mathrm{~b}$ & 79 & $120^{*}$ & $99 a$ & 53 & 66 & $59 \mathrm{a}$ \\
\hline Cereja Chipano & 149 & 154 & $151 \mathrm{~b}$ & 52 & 66 & $59 \mathrm{~b}$ & 43 & 48 & $46 \mathrm{~b}$ \\
\hline San Marzano & 186 & 191 & $188 \mathrm{a}$ & 68 & $111^{*}$ & $89 \mathrm{a}$ & 37 & 44 & $41 \mathrm{~b}$ \\
\hline Santa Clara & 171 & 157 & $164 \mathrm{~b}$ & 71 & 69 & $70 \mathrm{~b}$ & 40 & 33 & $36 \mathrm{~b}$ \\
\hline \multirow[t]{2}{*}{ Média } & 166 & 167 & & 67 & $91 *$ & & 43 & 48 & \\
\hline & \multicolumn{3}{|c|}{ 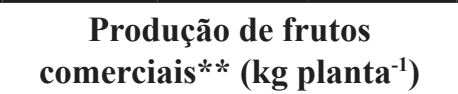 } & \multicolumn{3}{|c|}{ 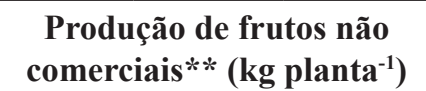 } & \multicolumn{3}{|c|}{$\begin{array}{l}\text { Peso médio de frutos } \\
\text { comerciais ( } \mathrm{g} \text { fruto }{ }^{-1} \text { ) }\end{array}$} \\
\hline Cereja 261 & 1,56 & 1,80 & $1,68 \mathrm{~b}$ & 0,33 & 0,38 & $0,35 \mathrm{a}$ & 35 & 33 & $34 \mathrm{c}$ \\
\hline Cereja Chipano & 1,97 & 1,54 & $1,75 \mathrm{~b}$ & 0,14 & 0,15 & $0,14 \mathrm{~b}$ & 15 & 16 & $16 \mathrm{~d}$ \\
\hline San Marzano & 2,76 & 3,60 & $3,18 \mathrm{a}$ & 0,21 & 0,52 & $0,36 \mathrm{a}$ & 114 & $172 *$ & $143 \mathrm{a}$ \\
\hline Santa Clara & 3,35 & 3,33 & $3,34 \mathrm{a}$ & 0,04 & 0,11 & $0,07 \mathrm{~b}$ & 107 & 120 & $113 \mathrm{~b}$ \\
\hline \multirow[t]{2}{*}{ Média } & 2,41 & 2,57 & & 0,18 & $0,29 *$ & & 68 & $85^{*}$ & \\
\hline & \multicolumn{3}{|c|}{$\begin{array}{l}\text { Diâmetro de frutos comerciais } \\
\qquad(\mathrm{mm})\end{array}$} & \multicolumn{3}{|c|}{$\begin{array}{c}\text { Sólidos solúveis totais nos } \\
\text { frutos }\left({ }^{\circ} \mathrm{Brix}\right)\end{array}$} & \multicolumn{3}{|c|}{ pH nos frutos } \\
\hline Cereja 261 & 40 & 39 & $40 \mathrm{c}$ & 6,0 & 6,3 & $6,1 \mathrm{a}$ & 4,2 & 4,2 & $4,2 \mathrm{~b}$ \\
\hline Cereja Chipano & 29 & 31 & $30 \mathrm{~d}$ & 5,8 & 6,2 & $6,0 \mathrm{a}$ & 4,2 & 4,1 & $4,1 \mathrm{~b}$ \\
\hline San Marzano & 53 & $57 *$ & $55 \mathrm{~b}$ & 4,7 & 4,7 & $4,7 \mathrm{~b}$ & 4,3 & 4,2 & $4,2 \mathrm{~b}$ \\
\hline Santa Clara & 56 & 58 & $57 \mathrm{a}$ & 5,5 & 5,7 & $5,6 \mathrm{a}$ & 4,2 & 4,5 & $4,4 \mathrm{a}$ \\
\hline \multirow[t]{2}{*}{ Média } & 45 & $46^{*}$ & & 5,5 & 5,7 & & 4,2 & 4,3 & \\
\hline & \multicolumn{3}{|c|}{$\begin{array}{c}\text { Acidez titulável nos frutos } \\
(\%)\end{array}$} & \multicolumn{3}{|c|}{$\begin{array}{c}\text { Teor de } \mathrm{N} \text { nos frutos } \\
\left(\mathrm{mg} \mathrm{N} \mathrm{kg}^{-1}\right)\end{array}$} & \multicolumn{3}{|c|}{$\begin{array}{c}\text { Teor de K nos frutos } \\
\left(\mathrm{mg} \mathrm{K} \mathrm{kg}^{-1}\right)\end{array}$} \\
\hline Cereja 261 & 0,32 & 0,37 & $0,34 \mathrm{a}$ & 24,9 & 23,4 & $24,1 \mathrm{ab}$ & 45,5 & 40,5 & $43,0 \mathrm{~b}$ \\
\hline Cereja Chipano & 0,33 & 0,35 & $0,34 \mathrm{a}$ & 20,7 & 20,8 & $20,7 \mathrm{~b}$ & 37,9 & 34,4 & $36,1 \mathrm{c}$ \\
\hline San Marzano & 0,33 & 0,34 & $0,34 \mathrm{a}$ & 21,3 & 22,7 & $22,0 \mathrm{~b}$ & 49,9 & 45,8 & $47,8 \mathrm{a}$ \\
\hline Santa Clara & 0,31 & 0,30 & $0,31 \mathrm{a}$ & 27,1 & 26,9 & $27,0 \mathrm{a}$ & 49,1 & 46,3 & $47,7 \mathrm{a}$ \\
\hline Média & 0,32 & 0,34 & & 23,5 & 23,4 & & 45,6 & $41,7^{*}$ & \\
\hline
\end{tabular}

**Peso fresco de frutos comerciais e não comerciais; Médias seguidas pela mesma letra na coluna não diferem pelo teste de Duncan, $\mathrm{p}<0,05$; *diferença significativa entre razões $\mathrm{N}$ :K pelo teste de Duncan, $\mathrm{p}<0,05$ (**fresh weight of comercial and non-comercial fruits; means followed by the same letter did not differ by Duncan test, $\mathrm{p}<0.05$; * significant difference between $\mathrm{N}: \mathrm{K}$ ratios by Duncan test, $\mathrm{p}<0.05$ ). 
Tabela 2. Características vegetativas, de frutos e teores de $\mathrm{N}$ e $\mathrm{K}$ na massa seca dos frutos, de quatro cultivares de tomateiro em cultivo fertirrigado sob duas razões $\mathrm{N}: \mathrm{K}$ aplicadas ao substrato (vegetative characteristics, fruit quality, and concentrations of $\mathrm{N}$ and $\mathrm{K}$ in fruits, of four tomato cultivars grown in fertigation system with two N:K ratios applied to the substrate). Seropédica, UFRRJ, 2007.

\begin{tabular}{|c|c|c|c|c|c|c|c|c|c|}
\hline \multirow{2}{*}{ Cultivar } & $\begin{array}{c}\text { Razão } \\
1: 2\end{array}$ & $\begin{array}{c}\text { Razão } \\
1: 3\end{array}$ & Média & $\begin{array}{c}\text { Razão } \\
1: 2\end{array}$ & $\begin{array}{c}\text { Razão } \\
1: 3\end{array}$ & Média & $\begin{array}{c}\text { Razão } \\
1: 2\end{array}$ & $\begin{array}{c}\text { Razão } \\
1: 3\end{array}$ & Média \\
\hline & \multicolumn{3}{|c|}{$\begin{array}{l}\text { Altura da planta } \\
(\mathrm{cm})\end{array}$} & \multicolumn{3}{|c|}{$\begin{array}{l}\text { Massa seca de folhas } \\
\left(\text { g planta }^{-1}\right)\end{array}$} & \multicolumn{3}{|c|}{$\begin{array}{c}\text { Massa seca de caule } \\
\left(\mathrm{g} \mathrm{planta}^{-1}\right)\end{array}$} \\
\hline Cereja 261 & 172 & 170 & $171 \mathrm{~b}$ & 44 & 54 & $49 \mathrm{a}$ & 43 & 45 & $44 \mathrm{a}$ \\
\hline Cereja Chipano & 184 & 161 & $172 \mathrm{~b}$ & 34 & 41 & $37 \mathrm{~b}$ & 29 & $37 *$ & $33 \mathrm{~b}$ \\
\hline San Marzano & 184 & 193 & $189 \mathrm{a}$ & 37 & $51 *$ & $44 \mathrm{ab}$ & 27 & $37 *$ & $32 \mathrm{~b}$ \\
\hline Santa Clara & 161 & 171 & $166 \mathrm{~b}$ & 31 & $43 *$ & $37 \mathrm{~b}$ & 24 & 30 & $27 \mathrm{c}$ \\
\hline \multirow[t]{2}{*}{ Média } & 175 & 174 & & 36 & $47 *$ & & 31 & $37 *$ & \\
\hline & \multicolumn{3}{|c|}{$\begin{array}{c}\text { Produção de frutos } \\
\left.\text { comerciais (kg planta }{ }^{-1}\right) *\end{array}$} & \multicolumn{3}{|c|}{$\begin{array}{c}\text { Produção de frutos } \\
\text { não comerciais }\left(\mathrm{kg} \mathrm{planta}^{-1}\right) * *\end{array}$} & \multicolumn{3}{|c|}{ 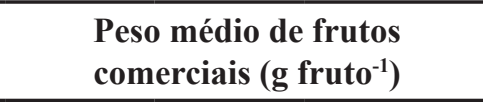 } \\
\hline Cereja 261 & 1,71 & 1,29 & $1,50 \mathrm{~b}$ & 0,26 & 0,21 & $0,24 \mathrm{a}$ & 31 & 34 & $33 \mathrm{c}$ \\
\hline Cereja Chipano & 1,46 & 1,70 & $1,58 \mathrm{~b}$ & 0,29 & 0,25 & $0,27 \mathrm{a}$ & 17 & 18 & $18 \mathrm{c}$ \\
\hline San Marzano & 2,11 & 2,42 & $2,26 \mathrm{a}$ & 0,46 & 0,75 & $0,60 \mathrm{a}$ & 137 & 136 & $137 \mathrm{a}$ \\
\hline Santa Clara & 2,32 & 1,76 & $2,04 \mathrm{ab}$ & 0,24 & 0,64 & $0,44 \mathrm{a}$ & 97 & 108 & $102 \mathrm{~b}$ \\
\hline \multirow[t]{2}{*}{ Média } & 1,90 & 1,79 & & 0,31 & 0,46 & & 71 & 74 & \\
\hline & \multicolumn{3}{|c|}{$\begin{array}{c}\text { Diâmetro de frutos } \\
\text { comerciais }(\mathrm{mm})\end{array}$} & \multicolumn{3}{|c|}{$\begin{array}{c}\text { Sólidos solúveis totais nos frutos } \\
\left({ }^{\circ} \text { Brix }\right)\end{array}$} & \multicolumn{3}{|c|}{ pH nos frutos } \\
\hline Cereja 261 & 38 & 38 & $38 \mathrm{~b}$ & 5,6 & 5,5 & $5,6 \mathrm{~b}$ & 4,1 & 4,0 & $4,1 \mathrm{~b}$ \\
\hline Cereja Chipano & 31 & 30 & $30 \mathrm{c}$ & 6,1 & 5,9 & $6,0 \mathrm{a}$ & 4,1 & 4,1 & $4,1 \mathrm{~b}$ \\
\hline San Marzano & 56 & 53 & $54 \mathrm{a}$ & 3,9 & 4,3 & $4,1 \mathrm{c}$ & 4,2 & 4,4 & $4,3 \mathrm{~b}$ \\
\hline Santa Clara & 53 & 51 & $52 \mathrm{a}$ & 4,1 & 3,5 & $3,8 \mathrm{c}$ & 4,5 & 4,4 & $4,5 \mathrm{a}$ \\
\hline \multirow[t]{2}{*}{ Média } & 44 & 43 & & 4,9 & 4,8 & & 4,2 & 4,2 & \\
\hline & \multicolumn{3}{|c|}{ Acidez titulável nos frutos (\%) } & \multicolumn{3}{|c|}{ Teor de $\mathrm{N}$ nos frutos $\left(\mathrm{mg} \mathrm{N} \mathrm{kg}^{-1}\right)$} & \multicolumn{3}{|c|}{ Teor de $\mathrm{K}$ nos frutos $\left(\mathrm{mg} \mathrm{K} \mathrm{kg}^{-1}\right)$} \\
\hline Cereja 261 & 0,39 & 0,35 & $0,37 \mathrm{a}$ & 17,3 & 16,9 & $17,1 \mathrm{a}$ & 40,2 & 37,1 & $38,6 \mathrm{~b}$ \\
\hline Cereja Chipano & 0,37 & 0,42 & $0,39 \mathrm{a}$ & 15,2 & 16,1 & $15,7 a b$ & 34,0 & 39,5 & $36,8 \mathrm{~b}$ \\
\hline San Marzano & 0,32 & 0,30 & $0,31 \mathrm{~b}$ & 15,5 & 12,7 & $14,1 \mathrm{~b}$ & 38,3 & 36,1 & $37,2 \mathrm{~b}$ \\
\hline Santa Clara & 0,31 & 0,34 & $0,32 \mathrm{~b}$ & 17,5 & 14,8 & $16,2 \mathrm{a}$ & 45,4 & 43,0 & $44,2 \mathrm{a}$ \\
\hline Média & 0,35 & 0,35 & & 16,4 & $15,1^{*}$ & & 39,5 & 38,9 & \\
\hline
\end{tabular}

**Peso fresco de frutos comerciais e não comerciais; Médias seguidas pela mesma letra na coluna não diferem pelo teste de Duncan, $\mathrm{p}<0,05$; *diferença significativa entre razões N:K pelo teste de Duncan, $\mathrm{p}<0,05$ (**fresh weight of comercial and non-comercial fruits; means followed by the same letter did not differ by Duncan test, $\mathrm{p}<0.05$; *significant difference between $\mathrm{N}: \mathrm{K}$ ratios by Duncan test, $\mathrm{p}<0.05$ ).

registrar o aumento de $6,5 \%$ na produção comercial na razão $\mathrm{N}: \mathrm{K} 1: 2 . \mathrm{Na}$ comparação das cultivares, Cereja 261 e San Marzano tiveram maior massa de folhas, a cultivar Cereja 261 maior massa de caule, e San Marzano plantas de maior altura (Tabela 1).

$\mathrm{Na}$ razão $\mathrm{N}: \mathrm{K} 1: 2$, houve aumento no peso e no diâmetro médio dos frutos comerciais da cultivar San Marzano (Tabela 1). A razão N:K 1:2 aumentou a produção de frutos não comerciais, em virtude da maior incidência de distúrbios fisiológicos como podridão apical e lóculo aberto (Tabela 1). As cultivares San Marzano e Santa Clara apresentaram maior produção de frutos comerciais, com frutos de maior peso e diâmetro médio (Tabela 1). Verificou-se um menor teor de sólidos solúveis na cultivar San Marzano e um maior $\mathrm{pH}$ nos frutos da cultivar Santa Clara, sem diferenças entre cultivares na acidez titulável (Tabela 1). Embora as razões N:K não tenham modificado a concentração de $\mathrm{N}$ na massa seca dos frutos, a concentração de $\mathrm{K}$ nos frutos reduziu-se na razão $\mathrm{N}: \mathrm{K}$ 1:2. Observou-se maior teor de $\mathrm{N}$ nos frutos da cultivar Santa Clara e maiores teores de K nos frutos de San Marzano e Santa Clara (Tabela 1).

No experimento fertirrigado, a ra- zão N:K 1:3 estimulou o crescimento vegetativo das plantas de tomateiro, com aumentos na massa seca de folha e caule (Tabela 2). A cultivar San Marzano apresentou plantas de maior altura, enquanto a Cereja 261 teve maior massa seca de folha e de caule. As diferentes razões N:K não modificaram a produção de frutos comerciais e não comerciais, o peso médio e o diâmetro dos frutos de tomateiro no sistema fertirrigado (Tabela 2). As cultivares San Marzano e Santa Clara tiveram maior produção de frutos comerciais, com frutos de maior diâmetro e peso médio (Tabela 2).

As razões $\mathrm{N}: \mathrm{K}$ não modificaram o 


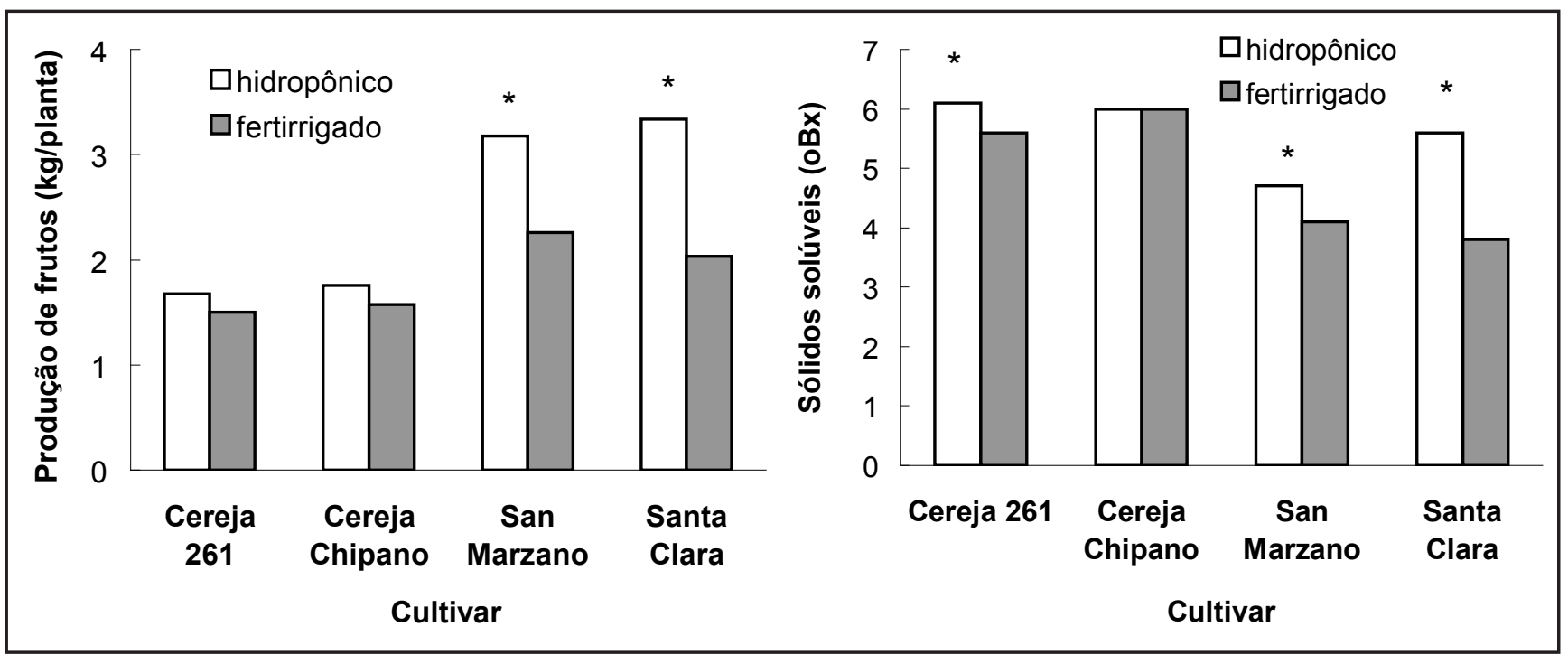

Figura 1. Produção de frutos comerciais e concentração de sólidos solúveis totais ( ${ }^{\circ}$ Brix) nos frutos, de quatro cultivares de tomateiro em cultivo hidropônico e cultivo fertirrigado (médias de duas doses de K) *diferença significativa entre experimentos pelo teste de Duncan, $\mathrm{p}<0,05$ (marketable fruit yield and concentration of total soluble solids ( ${ }^{\circ}$ Brix) in fruits of four tomato cultivars grown in hydroponics and fertirrigation systems (means of two K levels); *significant difference between experiments by Duncan test, $\mathrm{p}<0.05$ ). Seropédica, RJ, UFRRJ, 2007.

teor de sólidos solúveis totais, a acidez titulável e o $\mathrm{pH}$ dos frutos. Observou-se maior $\mathrm{pH}$ nos frutos da cultivar Santa Clara, e menor teor de sólidos solúveis e acidez titulável nos frutos das cultivares San Marzano e Santa Clara (Tabela 2). As razões N:K não modificaram a concentração de $\mathrm{K}$ na massa seca dos frutos, mas a razão $\mathrm{N}: \mathrm{K} 1: 3$ reduziu a concentração de $\mathrm{N}$ nos frutos. Observou-se maior teor de $\mathrm{N}$ nos frutos das cultivares Santa Clara e Cereja 261 e maior teor de K nos frutos de Santa Clara (Tabela 2).

A análise estatística conjunta dos dois experimentos indicou interações significativas entre experimentos e cultivares para alguns caracteres avaliados, demonstrando um comportamento diferencial das cultivares em cada sistema de cultivo.

A produção de frutos comerciais foi inferior no sistema fertirrigado, sendo esta redução significativa para San Marzano e Santa Clara, da ordem de 41 e 64\%, respectivamente (Figura 1). O híbrido Cereja Chipano e a cultivar Cereja 261 não apresentaram diferenças significativas na produção de frutos entre os dois sistemas (Figura 1), indicando que as cultivares com frutos tipo cereja mantiveram níveis de rendimento similares nos diferentes sistemas de cultivo. No sistema fertirrigado ocorreu uma redução no teor de sólidos totais nos frutos, em comparação ao sistema hidropônico, para todos os genótipos exceto o híbrido Cereja Chipano (Figura 1). Cabe ainda destacar a redução nos teores de $\mathrm{N}$ e $\mathrm{K}$ nos frutos no sistema fertirrigado em comparação ao hidropônico (Tabelas 1 e 2).

Considerando a densidade de 2,4 plantas por $\mathrm{m}^{2}$ de casa de vegetação nos dois experimentos, a produção média de frutos totais atingiu 4,9 e $4,2 \mathrm{~kg} \mathrm{~m}^{-2}$ para a cultivar Cereja 261, e 4,6 e 4,4 $\mathrm{kg} \mathrm{m}^{-2}$ para o híbrido Cereja Chipano, nos experimentos hidropônico e fertirrigado, respectivamente, na média das duas razões N:K (Tabelas 1 e 2). Gusmão et al. (2006), avaliando quatro cultivares de tomate cereja em cultivo protegido sob densidade de 4 plantas por $\mathrm{m}^{2}$, obtiveram produções totais de frutos entre 6 e $8 \mathrm{~kg} \mathrm{~m}^{-2}$, superiores às obtidas no presente trabalho (Tabelas 1 e 2). Já Feltrin et al. (2005), trabalhando em casa de vegetação com fertirrigação em solo, obtiveram produção de frutos de $3,8 \mathrm{~kg} /$ planta para a cultivar Swett Million (tipo cereja), produtividade superior à observada nas cultivares do tipo cereja no presente trabalho (Tabelas 1 e 2).

Para a cultivar San Marzano, a produção de frutos totais atingiu 8,5 e 6,9 $\mathrm{kg} \mathrm{m}^{-2}$, e a produção de frutos comerciais 7,6 e $5,4 \mathrm{~kg} \mathrm{~m}^{-2}$, nos experimentos hidropônico e fertirrigado, respectivamente, na média das duas razões $\mathrm{N}: \mathrm{K}$ (Tabelas 1 e 2). Machado et al. (2007), trabalhando a campo sob irrigação por gotejamento, obtiveram produtividades de frutos totais de 75 e $84 \mathrm{t} \mathrm{ha}^{-1}$, e de frutos comerciais de 64 e $69 \mathrm{t} \mathrm{ha}^{-1}$, para os híbridos Heinz 9780 e Kátia (ambos do tipo italiano), respectivamente, ou seja, similares às produtividades observadas no sistema hidropônico (Tabela 1). Para a cultivar Santa Clara, a produção média de frutos totais foi 8,2 e $5,9 \mathrm{~kg} \mathrm{~m}^{-2}$, e a produção de frutos comerciais 8,0 e 4,9 $\mathrm{kg} \mathrm{m}^{-2}$, nos experimentos hidropônico e fertirrigado, respectivamente (Tabelas 1 e 2). Caliman et al. (2005) verificaram produção comercial de $60 \mathrm{t} \mathrm{ha}^{-1}$ da cultivar Santa Clara em sistema protegido sob gotejamento, portanto inferior aos rendimentos obtidos pela cultivar Santa Clara no presente trabalho em sistema hidropônico (Tabela 1).

Os valores de sólidos solúveis totais mensurados nos frutos das cultivares do tipo cereja, da ordem de 5,6-6,1 ${ }^{\circ}$ Brix (Tabelas 1 e 2) foram ligeiramente superiores aos valores de 5,3 registrados por Feltrin et al. (2005) na cultivar Swett Milion (tipo cereja). Os teores de sólidos solúveis observados em San Marzano, de 4,7 no experimento hidropônico e 4,1 no fertirrigado (Tabelas 1 e 2), estão dentro da amplitude de 
3,9-5,0 ${ }^{\circ}$ Brix relatada por Carvalho et al. (2005) em quatro híbridos de tomate cultivados em ambiente protegido em substrato fertirrigado. Os frutos da cultivar Santa Clara apresentaram 5, $6^{\circ}$ Brix sob hidroponia, similares aos valores entre 5,0 e 5,4 observados por Feltrin et al. (2005) em duas cultivares do tipo salada. Valores entre 4,0 e $6,0{ }^{\circ}$ Brix são geralmente encontrados em cultivares de tomateiro, mas estes padrões podem sofrer variações em virtude do comportamento fisiológico da cultivar, do estádio de maturação do fruto, da estação do ano e de possíveis danos físicos e doenças do tomateiro (Filgueira, 2008). Frutos de tomateiro considerados adequados quanto ao uso para fins industriais devem apresentar sólidos solúveis totais acima de $4,0^{\circ}$ Brix (Silva \& Giordano, 2000).

O sistema hidropônico propiciou rendimento e qualidade de frutos superiores ao sistema fertirrigado (Figura 1). Uma solução nutritiva hidropônica pode favorecer o rápido crescimento e desenvolvimento de plantas, pois as concentrações dos elementos são estabelecidas no nível mais adequado possível, com ampla disponibilidade e sem produzir sintomas de toxicidade (Taiz \& Zeiger, 2004). Já no sistema fertirrigado, a disponibilidade dos nutrientes pode ser modificada pela capacidade de retenção de cátions do substrato, que pode diferir para cada elemento adicionado, modificando a disponibilidade e o balanço dos nutrientes fornecidos ao cultivo. Isto pode parcialmente explicar os efeitos mais acentuados da maior dose de $\mathrm{K}$ no sistema hidropônico do que no sistema fertirrigado, e os menores teores de $\mathrm{N} \mathrm{e}$ $\mathrm{K}$ nos frutos no experimento fertirrigado em comparação ao hidropônico (Tabelas 1 e 2). Os teores de $\mathrm{K}$ nos frutos no experimento em hidroponia (Tabela 1) estão próximos dos valores de $57 \mathrm{mg}$ $\mathrm{K} \mathrm{kg}^{-1}$ registrados por Fernandes et al. (2002) em frutos do híbrido Carmem em hidroponia.

A razão N:K 1:2 melhorou a qualidade dos frutos comerciais no sistema hidropônico, com aumentos no diâmetro e peso médio de frutos (Tabela 1). Entretanto, esta melhor qualidade de frutos sob maior disponibilidade de $\mathrm{K}$ foi associada a um menor teor de $\mathrm{K}$ nos frutos (Tabela 1), indicando que o K estaria atuando principalmente no estímulo à fotossíntese nas folhas e à translocação de assimilados, sem um efeito direto do $\mathrm{K}$ no metabolismo do fruto, como proposto por Kanai et al. (2007). O suprimento de K não modificou o $\mathrm{pH}$, a acidez titulável e o teor de sólidos solúveis totais dos frutos, tanto no sistema hidropônico quanto no fertirrigado (Tabelas 1 e 2), contrastando com os resultados de Fontes et al. (2000), que observaram redução no pH e aumento na acidez titulável em resposta a uma ampla faixa de variação de doses de K em fertirrigação. Por outro lado, Wright \& Harris (1985) verificaram um aumento no $\mathrm{pH}$ e na acidez titulável nos frutos de tomateiro no tratamento com as menores doses de $\mathrm{N}$ e $\mathrm{K}$ aplicadas. Isto indica que os efeitos do suprimento de $\mathrm{K}$ em parâmetros sensoriais e de qualidade de frutos de tomate podem variar em resposta a diferentes condições ambientais e à amplitude das doses de $\mathrm{K}$ avaliadas.

Conclui-se que o sistema hidropônico propiciou maiores produção e qualidade de frutos de tomateiros dos tipos italiano (San Marzano) e salada (Santa Clara), em comparação ao sistema fertirrigado. O rendimento das cultivares tipo cereja foi similar nos sistemas hidropônico e fertirrigado. No sistema hidropônico, a utilização de uma solução de Hoagland \& Arnon diluída a $50 \%$ com razão N:K 1:2 forneceu frutos de maior qualidade comercial.

\section{AGRADECIMENTOS}

Agradecemos ao CNPq pela bolsa de doutorado concedida ao primeiro autor, e às empresas Hidrogood, Qualifertil, Dancor e Isla, pelos materiais cedidos para condução dos experimentos.

\section{REFERÊNCIAS}

ALVARENGA MAR; LIMA LA; FAQUIN V. 2004. Fertirrigação. In: ALVARENGA MAR (ed). Tomate: produção em campo, em casade-vegetação e em hidroponia. Lavras: Editora UFLA. p.121-158.

ANDRIOLO JL; DUARTE TS; LUDKE L; SKREBSKY EC. 1997. Crescimento e desenvolvimento do tomateiro cultivado em substrato com fertirrigação. Horticultura
Brasileira 15: 28-32.

CALIMAN FRB; SILVA DJH; FONTES PCR; STRINGUETA PC; MOREIRA GR; CARDOSO AA. 2005. Avaliação de genótipos de tomateiro cultivados em ambiente protegido e em campo nas condições edafoclimáticas de Viçosa. Horticultura Brasileira 23: 255-259.

CARVALHO LA; NETO JT; ARRUDA, MC; JACOMINO AP; MELO PCT. 2005. Caracterização físico-química de híbridos de tomate de crescimento indeterminado em função do espaçamento e número de ramos por planta. Revista Brasileira de Agrociência 11: 295-298.

CHEN J; GABELMAN WH. 2000. Morphological and physiological characteristics of tomato roots associated with potassium-acquisition efficiency. Scientia Horticulturae 83: 213225.

FAYAD JA; FONTES PCR; CARDOSO AA; FINGER FL; FERREIRA FA. 2002. Absorção de nutrientes pelo tomateiro cultivado sob condições de campo e de ambiente protegido. Horticultura Brasileira 20: 90-94.

FELTRIN DM; POTT CA; FURLANI PR; CARVALHO CRL. 2005. Produtividade e qualidade de frutos de cultivares de tomateiro fertirrigado com cloreto e sulfato de potássio. Revista de Ciências Agroverterinárias 4: 17-24.

FERNANDES AA; MARTINEZ HEP; FONTES PCR. 2002. Produtividade, qualidade de frutos e estado nutricional do tomateiro tipo longa vida conduzido com um cacho, em cultivo hidropônico, em função das fontes de nutrientes. Horticultura Brasileira 20: 564-570.

FILGUEIRA FAR. 2008. Novo manual de olericultura: agrotecnologia moderna na produção e comercialização de hortaliças. $3^{\mathrm{a}}$ ed. Viçosa: UFV. 421p.

FONTES PCR; SAMPAIO RA; FINGER FL. 2000. Fruit size, mineral composition and quality of trickle-irrigated tomatoes as affected by potassium rates. Pesquisa Agropecuária Brasileira 35: 21-25.

GARGANTINI H.; BLANCO HG. 1963. Marcha de absorção de nutrientes pelo tomateiro. Bragantia 56: 693-714.

GENUNCIO GC; MAJEROWICZ N; ZONTA E; SANTOS AM; GRACIA D; AHMED CRM; SILVA MG. 2006. Crescimento e produtividade do tomateiro em cultivo hidropônico NFT em função da concentração iônica da solução nutritiva. Horticultura Brasileira 24: 175-179.

GUALBERTO R; BRAZ LT; BANZATTO DA. 2002. Produtividade, adaptabilidade e estabilidade fenotípica de cultivares de tomateiro sob diferentes condições de ambiente. Pesquisa Agropecuária Brasileira 37: 81-88.

GUSMÃO MTA; GUSMÃO SAL; ARAÚJO JAC. 2006. Produtividade de tomate tipo cereja cultivado em ambiente protegido e em diferentes substratos. Horticultura Brasileira 24: 431-436.

HEBBAR SS; RAMACHANDRAPPA BK; NANJAPPA HV; PRABHAKAR M. 2004. Studies on NPK drip fertigation in field grown 
tomato (Lycopersicon esculentum Mill.). European Journal of Agronomy 21: 117-127.

INSTITUTO ADOLFO LUTZ. 1985. Normas analíticas do Instituto Adolfo Lutz: métodos químicos e físicos para análises de alimentos. $3^{\text {a }}$ ed. São Paulo: Instituto Adolfo Lutz. $533 \mathrm{p}$.

ISLA. Isla Sementes. Disponível em: www.isla. com.br Acesso em: 20 de agosto de 2009.

KANAI S; OHKURA K; ADU-GYAMFI JJ; MOHAPATRA PK; NGUYEN NT; SANEOKA H; FUJITA K. 2007. Depression of sink activity precedes the inhibition of biomass production in tomato plants subjected to potassium deficiency stress. Journal of
Experimental Botany 58: 2917-2928

MACHADO AQ; ALVARENGA MAR; FLORENTINO CET. 2007. Produção de tomate italiano (saladete) sob diferentes densidades de plantio e sistemas de poda visando ao consumo in natura. Horticultura Brasileira 25: 149-153.

MELO PCT; MIRANDA JEC; COSTA CP. 1988. Possibilidades e limitações do uso de híbridos $\mathrm{F}_{1}$ de tomate. Horticultura Brasileira 6: 4-7.

MORAES CAG. 1997. Hidroponia: Como cultivar tomates em sistema NFT. Jundiaí: DISQ Editora. 143p.

PRADOS NC. 2001. Manejo del cultivo intensivo com suelo. In: NUEZ F (ed). El cultivo del tomate. Madrid: Mundi-Prensa. p.190-225.
SILVA JBC; GIORDANO LB. 2000. Tomate para processamento industrial. Brasília: Embrapa Hortaliças. 168p.

TAIZ L; ZEIGER E. 2004. Fisiologia Vegetal. $3^{\mathrm{a}}$ ed. Porto Alegre: Artmed. 719p.

TEDESCO MJ; GIANELLO C; BISSANI CA; BOHNEN H; VOLKWEISS SJ. 1995. Análise de solo, plantas e outros materiais. Porto Alegre: Departamento de Solos/UFRGS. 174p. (Boletim Técnico, 5).

WRIGHT DH; HARRIS ND. 1985. Effect of nitrogen and potassium fertilization on tomato flavor. Journal of Agricultural and Food Chemistry 33: 355-358. 